\title{
The concept of the insulin intestinal uptake mechanism: Associated with polymeric nanoparticles
}

\author{
Rabiee N* \\ Department of Chemistry, Shahid Beheshti University, Tehran, Iran
}

\begin{abstract}
Diabetes mellitus is usually a substantial frequency and among the many serious and lethal illnesses in the globe. Insulin is definitely generally utilized to deal with diabetes to be able to provide individuals a much better existence state. Nevertheless, because of bioavailability complications, the most typical path of insulin operations can be the subcutaneous path that might present individuals conformity complications to treatment. The dental administration is certainly therefore regarded as the majority of hassle-free option to deliver insulin, nevertheless it encounters essential difficulties. The poor balance of insulin in the stomach tract and poor digestive tract permeation, are complications to conquer. Consequently, the encapsulation of insulin into polymer-based nanoparticles is usually offered as a great technique to boost insulin bioavailability.
\end{abstract}

\section{Mechanism of the Insulin Intestinal uptake: Toward polymeric nanoparticles}

Irrespective belonging to the conferred coverage of insulin through nanoparticles (NPs) from the aggressive circumstances of the stomach pathway, the transportation throughout the digestive tract epithelium even now continues to be a hurdle to conquer. Since a gatekeeper, the epithelium functions by thwarting protein from becoming assimilated, which makes it the main limited hurdle to the NPs passing from the lumen to the lamina propria [1-5].

The epithelial cellular material preserve this safety due to the limited junctions among surrounding cellular material. Therefore, the transportation and the absorption system may become possibly paracellular (between the cellular material) or transcellular (by using the cellular material), and are primarily controlled by the features of the mucosa and as well, by the physicochemical features of the NPs this kind of as size, charge and lipophilicity. It is usually generally approved that because of to the features of the paracellular path, which offers a little surface area region (much less than $1 \%$ of the total intestinal tract) and a limited space owing to the tightness of the junctions between cellular material ( 3 and $10 \AA$ of size), this is definitely not really the most typical system of NPs subscriber base. Nevertheless, it provides been explained that some organic polymers utilized in NPs structure this kind of as chitosan, may reversibly impact the restricted junctions starting by systems that are still not really extremely well comprehended. For example, some components may take action on the limited junctions causing a structural reorganization of their healthy proteins and others may modulate restricted junctions by chelating calcium mineral and causing their disruption. The transcellular transportation can be therefore the majority of possible system of NPs absorption. This transportation path might end up being split up into diverse endocytic systems: phagocytosis, macropinocytosis, clathrinmediated endocytosis and caveole-mediated endocytosis, which are adenosine triphosphate (ATP) dependents, and clathrin- and caveolaeindependent endocytosis, that are not really ATP dependents. These subscriber base systems happen at the apical cellular membrane layer, in which NPs will be taken-up, and after that the transportation happens by using cellular material inside vesicles, liberatitheir material at the basolateral pole [6-10]

In the epithelial cellular material, phagocytosis is certainly limited to $\mathrm{M}$ cellular material that is usually a receptor-mediated procedure in which the mobile membrane layer tasks on its own to engulf NPs. $\mathrm{M}$ cellular material possess a number of properties that mementos the transportation of NPs this kind of as absence of mucus release, a short glycocalyx and decreased proteases, producing the transportation by using $\mathrm{M}$ cellular material more significant than the transportation simply by enterocytes. Nevertheless, as $\mathrm{M}$ cellular material are component of the immune Peyer's areas, it may activate the immune reactions diminishing additional the NPs administration. Comparable to phagocytosis, also macropinocytosis is definitely an actin-dependent procedure able of engulf huge quantities of liquid that contains NPs; nevertheless, this can be not really limited to a mobile type and it is certainly nonspecific receptor mediated. The vesicles could have got a big size (between 0.15-5 $\mu \mathrm{M}$ ) and following created, they blend with the premature endosomes. Clathrin-mediated endocytosis, in change, is usually a receptor-mediated subscriber base where the mobile membrane layer forms pits beginning little vesicles covered by aminoacids (generally clathrin proteins), which also blend with early endosomes. One technique to improve the NPs subscriber base simply by the digestive tract cellular material is definitely to conjugate ligands to NPs surface area that might help cell-NP relationships and improve the NPs internalization. Bacterial adhesins, lectins, monoclonal antibodies and particular amino acidity sequences are a few good examples of ligands which could become discovered in additional fine detail somewhere else. At last, caveole-mediated endocytosis can be a

${ }^{\star}$ Correspondence to: Navid Rabiee, Invited Scientist, Department of Chemistry, Shahid Beheshti University, Tehran, Iran, E-mail: nrabiee94@gmail.com

Key words: diabetes mellitus, insulin, polymeric nanoparticles, intestinal uptake

Received: July 09, 2018; Accepted: July 23, 2018; Published: July 25, 2018 
nonspecific subscriber base procedure wherever little caveolae-coated vesicles $(50-80 \mathrm{~nm})$ can get away from the endolysosomes and result in immediate exocytosis. Nevertheless, the little size of the vesicles causes this a non-probable path of NPs uptake [11-15].

\section{References}

1. Damgé C, Maincent P, Ubrich N (2007) Oral delivery of insulin associated to polymeric nanoparticles in diabetic rats. $J$ Control Release 117: 163-170. [Crossref]

2. Cui F (2006) Biodegradable nanoparticles loaded with insulin-phospholipid complex for oral delivery: preparation, in vitro characterization and in vivo evaluation. Journal of controlled release 114: 242-250.

3. Damgé C, Reis CP, Maincent P (2008) Nanoparticle strategies for the oral delivery of insulin. Expert Opin Drug Deliv 5: 45-68. [Crossref]

4. Pridgen EM, Alexis F, Farokhzad OC (2014) Polymeric nanoparticle technologies for oral drug delivery. Clinical Gastroenterology and Hepatology 12: 1605-1610. [Crossref]

5. Ahmadi S, Rabiee N, Rabiee M (2018) Application of Aptamer-based hybrid molecules in early diagnosis and treatment of diabetes mellitus: From the concepts toward the Future. Current diabetes reviews 6. [Crossref]

6. Woitiski CB, Carvalho RA, Ribeiro AJ, Neufeld RJ, Veiga F (2008) Strategies toward the improved oral delivery of insulin nanoparticles via gastrointestinal uptake and translocation. BioDrugs 22: 223-237. [Crossref]
7. Huang YF, Chang HT (2007) Analysis of adenosine triphosphate and glutathione through gold nanoparticles assisted laser desorption/ionization mass spectrometry. Analytical chemistry 79: 4852-4859. [Crossref]

8. Harush-Frenkel O, Debotton N, Benita S, Altschuler Y (2007) Targeting of nanoparticles to the clathrin-mediated endocytic pathway. Biochemical and biophysical research communications 353: 26-32. [Crossref]

9. Sahay G, Alakhova DY, Kabanov AV (2010) Endocytosis of nanomedicines. J Control Release 145: 182-195. [Crossref]

10. Chen MC, Sonaje K, Chen KJ, Sung HW (2011) A review of the prospects for polymeric nanoparticle platforms in oral insulin delivery. Biomaterials 32: 9826-9838. [Crossref]

11. Bhumkar DR, Joshi HM, Sastry M, Pokharkar VB (2007) Chitosan reduced gold nanoparticles as novel carriers for transmucosal delivery of insulin. Pharmaceutical research 24: 1415-1426. [Crossref]

12. Jung T, Kamm W, Breitenbach A, Kaiserling E, Xiao JX, Kissel T (2000) Biodegradable nanoparticles for oral delivery of peptides: is there a role for polymers to affect mucosal uptake? European Journal of Pharmaceutics and Biopharmaceutics 50: 147-160. [Crossref]

13. Mohanraj V, Chen Y (2006) Nanoparticles-a review. Tropical journal of pharmaceutical research 5: 561-573.

14. Cartiera MS, Johnson KM, Rajendran V, Caplan MJ, Saltzman WM (2009) The uptake and intracellular fate of PLGA nanoparticles in epithelial cells. Biomaterials 30: 27902798. [Crossref]

15. Sarmento B, Ribeiro A, Veiga F, Sampaio P, Neufeld R (2007) Alginate/chitosan nanoparticles are effective for oral insulin delivery. Pharmaceutical research 24: 2198 2206. [Crossref]

Copyright: (C2018 Rabiee N. This is an open-access article distributed under the terms of the Creative Commons Attribution License, which permits unrestricted use, distribution, and reproduction in any medium, provided the original author and source are credited. 